\title{
Screening of Endocrine Disrupting Chemicals Using a Surface Plasmon Resonance Sensor
}

\author{
Kazunobu Asano, ${ }^{\dagger}$ Atsushi Ono, Setsuko Hashimoto, Tohru Inoue, and Jun Kanno \\ New Business Development, Biacore K.K., Koyo Bldg. 5F, 2-9-5 Shiba Koen, \\ Minato-ku, Tokyo 105-0011, Japan
}

\begin{abstract}
Because concern over endocrine disrupting reactions caused by chemicals to humans and animals is growing, a rapid and reliable screening assay for endocrine disrupting chemicals is required. We have developed an in vitro screening assay based on a hormone receptor mechanism using a surface plasmon resonance (SPR) sensor. The interaction between an estrogen receptor $\alpha(E R)$ and an estrogen response element (ERE) is monitored in real time, when ER is injected over the SPR sensor chip on which a DNA fragment containing ERE is immobilized. In the presence of a chemical with estrogenic activity, the ER-ERE interaction is enhanced and the kinetic parameters are altered. We have validated the assay in terms of its specificity, dose dependency, optimal reaction conditions and reproducibility. It has been shown that the assay is very reliable as a rapid and quantitative screening method to judge the estrogenic activities of chemicals.
\end{abstract}

\section{Introduction}

Recently, concern has grown that some chemicals, such as organic chloride insecticides, plasticizers and detergents can cause endocrine disrupting effects to wild animals and humans. ${ }^{1}$ Many of them are supposed to pose endocrine disrupting activities through direct interaction with the hormone receptors, such as estrogen receptor, thus modifying or inhibiting the physiological hormonal activities. ${ }^{2}$ Chemical safety is evaluated by a set of the toxicological tests, such as carcinogenicity, teratogenicity, mutagenicity, reproduction tests. However, they have limitation to evaluate the chronic toxicity of chemicals. Moreover, the mechanisms of the endocrine disrupting activities are yet to be elucidated and the test methods to evaluate the effects are not well established. ${ }^{3}$

Several test methods have been reported to detect the endocrine disrupting activities caused by hormone receptors, i.e. competitive receptor binding assay, a cell growth assay using breast cancer cells expressing the estrogen receptors (MCF7), ${ }^{4}$ cell-based reporter assay, ${ }^{5}$ an in vivo rodent uterotrophic test, ${ }^{6,7}$ and a vitellogenin assay using medaka fish (Oryzias latipes). ${ }^{8}$ Many of these methods require a long time to obtain results. Furthermore, the endocrine disrupting activities can not always be detected when the chemicals are administered to the animals due to physiological regulations concerning the animal bodies. It is not easy to detect the hormonal effects of chemicals. The existing toxicological methods are not always the best way to detect the effects which have the feedback mechanism or the effects via the receptors. Therefore, a novel approach is sought for the rapid assessment of the endocrine disrupting activities of the chemicals.

The hormone receptors are the ligand dependent transcription factors. For example, estrogen receptor (ER) changes its

† To whom correspondence should be addressed.

This is an English edition of the paper which won the Best Paper Award in Bunseki Kagaku, 2002 [Bunseki Kagaku, 2002, 51(6), 389]. conformation upon binding of the endogenous ligand, estrogen, and binds to the specific sequence of the DNA located upstream of the target genes and activates transcription of the genes (Fig. 1). Many chemicals with diverse structures have been reported to have estrogenic activities. Due to the variety of the structure, it is unlikely that all the chemicals act with the same mechanism. Each chemical may pose a different regulatory effect on the gene expression. ${ }^{9}$

Recently, a surface plasmon resonance (SPR) sensor is emerging as a novel analytical instrument. ${ }^{10}$ The SPR sensor has features that it can monitor molecular interaction without labeling the molecules in real time. It is, therefore, suitable for high throughput screening assays. Compared to the existing technologies which monitor the binding amounts at the end of the interactions, the SPR sensor is unique to be able to detect the processes throughout the association and the dissociation of the interaction. This feature enables detailed analyses of chemical effects to receptors.

We have established a cell free screening assay focusing on the hormone receptor mechanism as a high throughput screening method for the endocrine disrupting chemicals. In order to measure the interaction of the biological molecules using the SPR sensor, one of the test molecules is immobilized

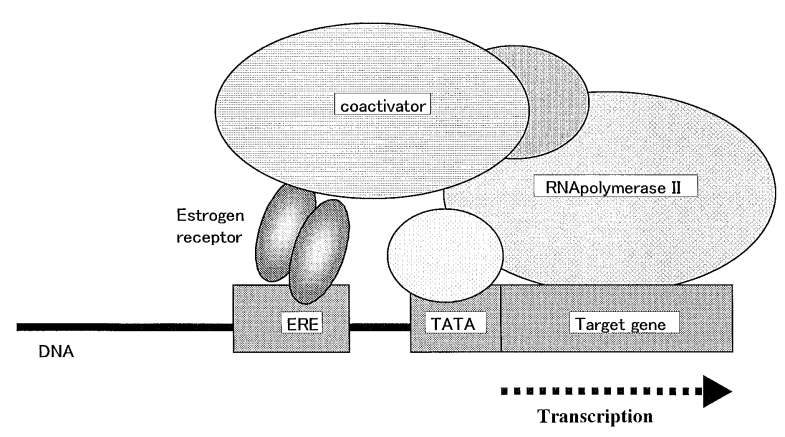

Fig. 1 Functional mechanism of the estrogen receptor in gene regulation. 


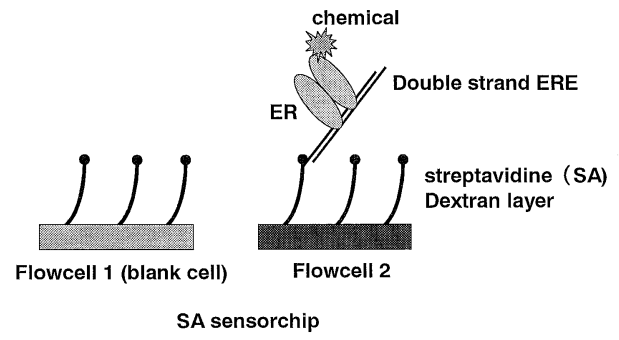

Fig. 2 Scheme of the ER-ERE assay with an SPR sensor.

on the sensor chip surface and a solution containing the other molecule is passed over the sensor surface at a constant flow rate through the microfluidics. A small mass changes, resulting from the binding and the dissociation of the two molecules on the sensor surface is monitored as SPR signals. The time course of the changes in the SPR signals is displayed as a curve called a sensorgram. Unlike from the conventional technologies, the SPR sensor can measure the interactions using a small amount of non-labeled samples within a short time. With regard to the interaction of the molecules, the SPR sensor can give not only the affinity of the two molecules at the equilibrium (as the dissociation constant, $K_{\mathrm{D}}$ or the affinity constant, $K_{\mathrm{A}}$ ) but also the information on two molecules binding or dissociation velocity, namely the association rate constant $\left(k_{\mathrm{a}}\right)$ and the dissociation rate constant $\left(k_{\mathrm{d}}\right)$.

We have designed an assay to monitor the interaction of estrogen receptor $\alpha(\mathrm{ER})$ and the estrogen response element $(\mathrm{ERE})^{11}$ that is located in the promoter region of the estrogen target genes by immobilizing the DNA fragment containing the ERE sequence on the sensor chip and injecting purified ER over the sensor chip (Fig. 2). Thirty chemicals were tested for the estrogenic activities.

\section{Experiments}

\section{Reagents and instruments}

Reagent. Tricine, $\mathrm{CaCl}_{2}, \mathrm{MgCl}_{2}, \mathrm{KOH}$, Tween 20, $\mathrm{NaOH}$ and $\mathrm{HCl}$ were purchased from Nacalai Tesque and DMSO from Sigma. Estrogen receptor (ER) was purchased from PanVera. ER was aliquoted into $5 \mu \mathrm{l}$ and stored at $-80^{\circ} \mathrm{C}$. Biotinylated estrogen response element (ERE) DNA (5'-biotintcgagcaaagtcaggtcacagtgacctgatcaat- $3^{\prime}$ ) of viterogenin gene and the anti-strand DNA have been synthesized by Nisshinbo. The synthesized oligomers were diluted with MilliQ water to 1 $\mathrm{mg} / \mathrm{ml}$ and stored at $-20^{\circ} \mathrm{C}$. The running buffer for Biacore 3000 was prepared by filtering a solution of $25 \mathrm{mM}$ Tricine, 160 $\mathrm{mM} \mathrm{KCl}, 5 \mathrm{mM} \mathrm{MgCl}$ (pH 7.8), 0.05\% Tween 20.

Instrument. The assay was performed using Biacore 3000 (Biacore $\mathrm{AB}$ ), the heat block (EYELA) and the circulator (Asone). Sensor chip SA (Biacore AB) was used. Through the assay, the sample rack of Biacore instrument was cooled to $4^{\circ} \mathrm{C}$ by connecting the circulator to the instrument and the reaction was run at $25^{\circ} \mathrm{C}$.

\section{Operation}

Immobilization of biotinylated ERE. For the immobilization of biotinylated ERE to the sensor chip, a streptoavidin preimmobilized sensor chip (Sensor chip SA) was set to the Biacore 3000 instrument and the instrument was equilibrated with running buffer. In order to stabilize the sensor surfaces, $100 \mathrm{mM} \mathrm{NaOH}$ and $50 \mathrm{mM} \mathrm{HCl}$ were injected for 30, 5 times.

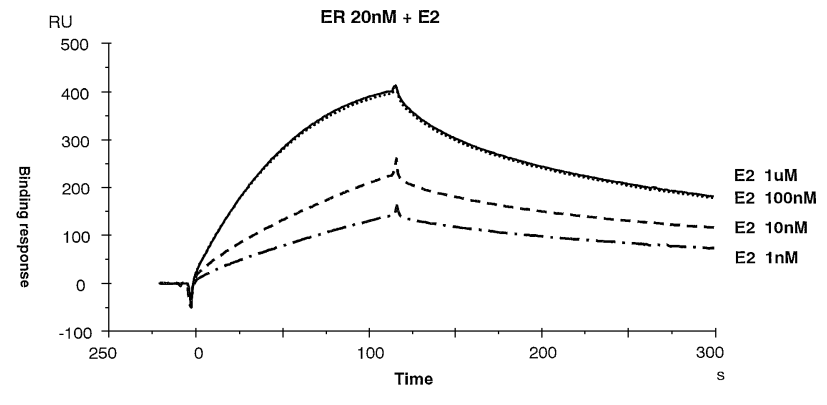

Fig. 3 Dose-dependent responses of E2.

After checking the baseline stability, we performed immobilization of the biotinylated ERE. Biotinylated ERE (1 $\mathrm{mg} / \mathrm{ml}$ ) was diluted hundred thousand times with the running buffer. Then, $100 \mu \mathrm{l}$ of the ERE solution was heated in boiling water for $5 \mathrm{~min}$ and chilled rapidly to denature the biotinylated ERE. The solution was injected over the sensor surface to immobilize approximately $60 \mathrm{RU}$ onto the SA sensor chip surface. Then, the complementary ERE $(1 \mathrm{mg} / \mathrm{ml})$ was diluted to 100 times with the running buffer and denatured by the same method. This solution was injected for 2 min over the sensor surface where the biotinylated ERE was immobilized to form double stranded ERE on the surface. Biotin $(1 \mu \mathrm{g} / \mathrm{ml})$ was injected to block free SA on the sensor surface. A separate flow cell was used as a blank cell on which only biotin was immobilized.

Preparation of the test chemicals. Each chemical was dissolved with $100 \%$ DMSO to make $0.1 \mathrm{M}$ stock solution, and stored at $-80^{\circ} \mathrm{C}$. Immediately before the assay, $1 \mu \mathrm{l}$ of the stock solution was diluted 500 times using the chilled running buffer. Also ER stock solution was diluted to $40 \mathrm{nM}$ using a chilled running buffer. A $50-\mu \mathrm{l}$ volume of the ER solution and $50 \mu \mathrm{l}$ of the chemical solution of each concentration were mixed to give final concentrations of $20 \mathrm{nM}$ ER and $10 \mu \mathrm{M}$ to $1 \mathrm{nM}$ of the chemical. The samples were kept at $4^{\circ} \mathrm{C}$ in a sample rack to maintain the ER activity. $17 \beta$-Estradiol was used as a positive control. First, we prepared the various concentration of $17 \beta$ estradiol ( $1 \mu \mathrm{M}$ to $1 \mathrm{nM}$ ) and measured the binding of ER to ERE (Fig. 3). As the binding activity of ER to ERE was plataued over $100 \mathrm{nM} \mathrm{17} \beta$-estradiol, we decided to use $100 \mathrm{nM}$ $17 \beta$-estradiol as a positive control in the following experiments. We also prepared a negative control solution which did not contain any chemicals. After the preparation of samples, the samples were treated at $37^{\circ} \mathrm{C}, 5 \mathrm{~min}$ and rapidly cooled. The samples were then set on the sample rack for measurements.

Assay of ER and ERE. The prepared samples were injected for 2 min at a flow rate of $20 \mu \mathrm{l} / \mathrm{min}$ over the immobilized ERE and the blank flowcell. Injection command of "kinject" was used and the dissociation phase was monitored for $2 \mathrm{~min}$. The "kinject" command is one of the injection commands specially designed for the kinetic analysis in the Biacore instrument. Upon injecting the samples using "kinject" command, the sample solution was clearly separated by two air plugs at the both ends of the sample solution from the running buffer in order to prevent the sample solution from being diluted by the running buffer. The command is also designed to monitor dissociation of the bound molecule without being disturbed by the movement of the injection needle for the set period of time. After monitoring the binding and dissociation, $100 \mathrm{mM} \mathrm{NaOH}$ and $50 \mathrm{mM} \mathrm{HCl}$ were injected $30 \mathrm{~s}$ each for regeneration of the sensor surfaces. All the measurements were run automatically. 

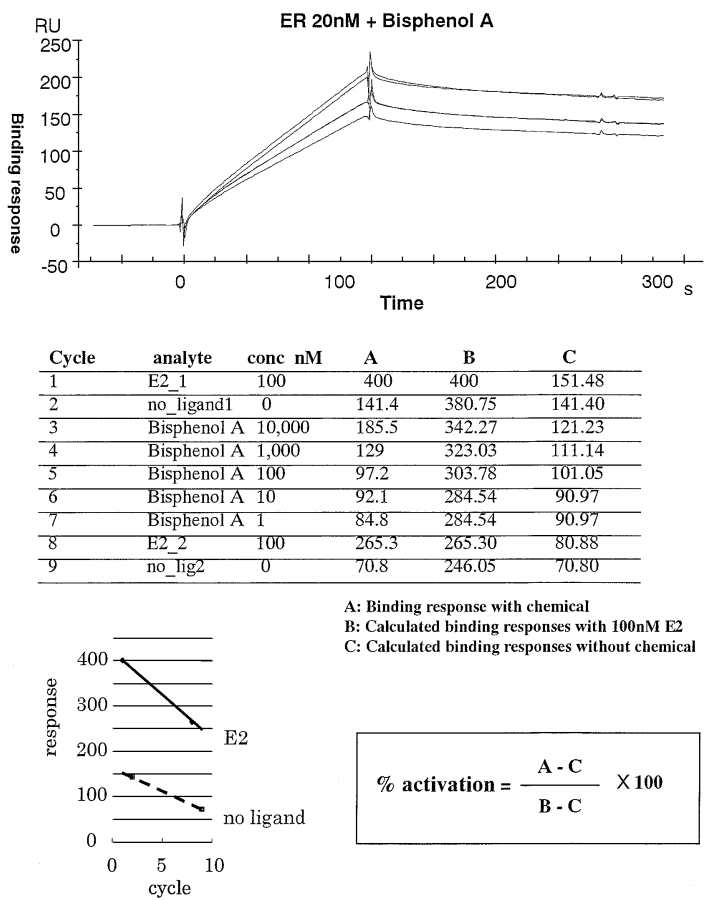

Fig. 4 Data evaluation of chemical screening.

\section{Data evaluation}

A set of the assay consisted of 5 concentrations of the test chemical, a negative control (no chemical) and a positive control (100 nM 17 $\beta$-estradiol). The results were compared as the ratio to the positive control (\% activation). ER was unstable and lost its binding activity to ERE during the assay period in spite of optimizing the assay conditions. We have developed an assay design to correct for any loss of the binding activity of ER over time. A positive control cycle and a negative control cycle were run at the beginning and the end of the assay. The binding responses were recorded. Based on the rate of loss in the positive and negative control samples, the binding responses of the positive and negative controls for each cycle were calculated. The enhancement of ER binding by the test chemical was expressed as the ratio to those by the positive control of $100 \mathrm{nM} 17 \beta$-estradiol, namely as a relative activation (\% activation) using the formula and the corrected binding signals, as shown in Fig. 4.

\section{Results}

Validation of the ER-ERE assay using Biacore

In order to confirm the significance of the ER assay, the binding of ER to ERE was tested with a varying concentration of ER. The binding signals increased in relation to the increasing concentrations of ER. ER did not bind to the sensor surface where no ERE was immobilized (Fig. 5). A $1 \mu \mathrm{M}$ volume of BSA did not show any significant binding to ERE surfaces (Fig. 6). These observations indicate that the assay monitors the specific binding of ER to ERE. Comparing the results with 10, 20 and $40 \mathrm{nM}$ ER, we often observed relatively low binding signals with $10 \mathrm{nM}$ ER. Higher binding signals were obtained by adding a final concentration of $1 \mu \mathrm{M}$ BSA to $10 \mathrm{nM}$ ER. Due to the low protein concentration, ER was lost by absorption to the surfaces of the plastic vials and tips and the actual concentration of ER became lower than $10 \mathrm{nM}$. Based on

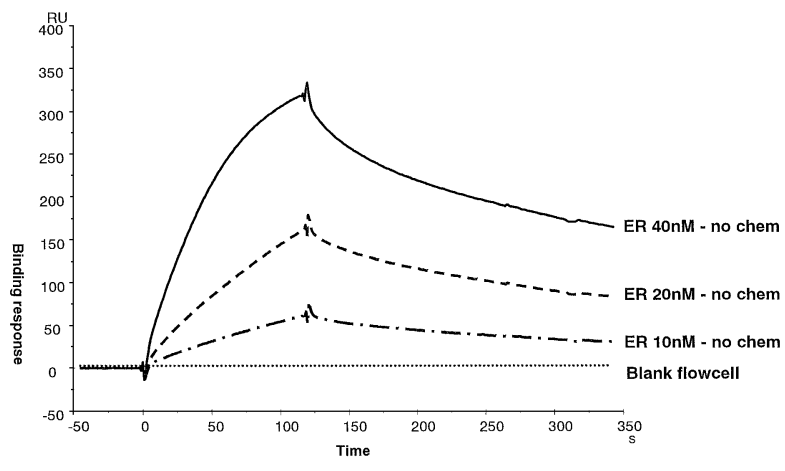

Fig. 5 Dose-dependent responses of ER-1.

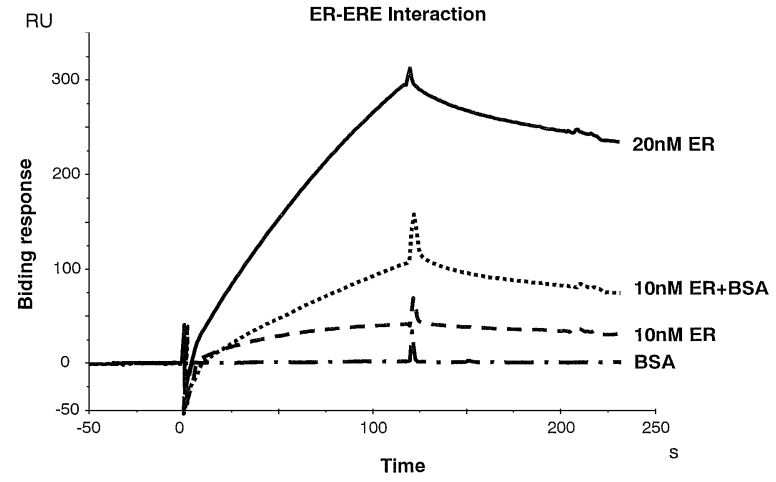

Fig. 6 Dose-dependent responses of ER-2.
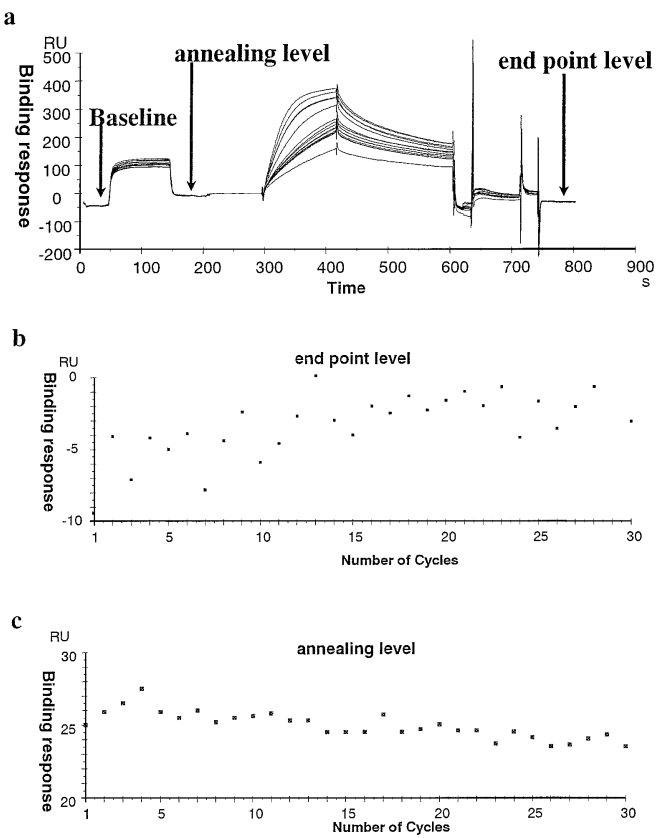

Fig. 7 Reproducibility of the ER-ERE assay.

those results, we decided to run the following assays with the final ER concentration of $20 \mathrm{nM}$.

It is important to regenerate the sensor surfaces to achieve reproducible results in the Biacore assay. We have repeated 30 cycles of the assay (Fig. 7a) and monitor the end point levels (Fig. 7b). It was confirmed that the sensor surfaces were properly regenerated and the assay showed high reproducibility. 


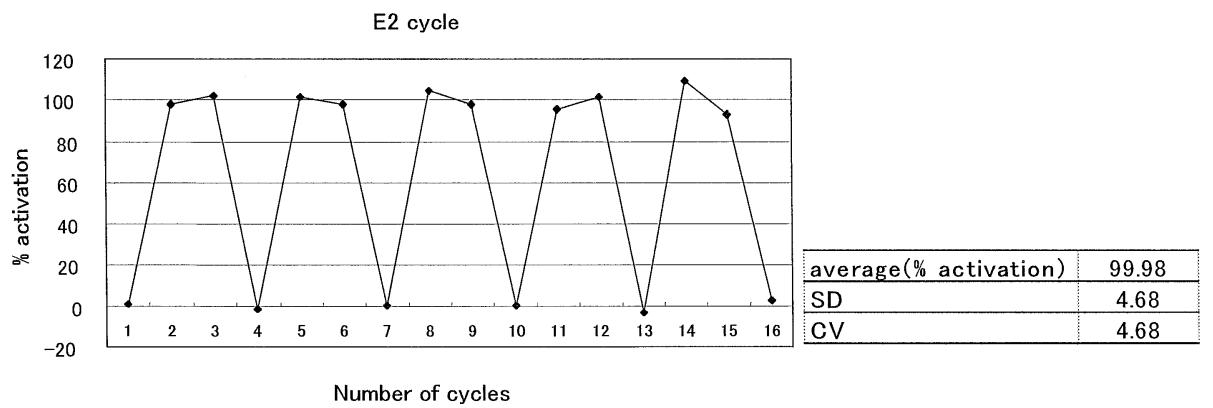

Fig. 8 Precision of the ER-ERE assay.

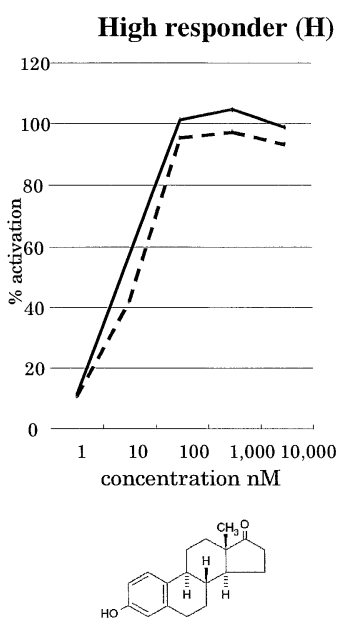

Estrone

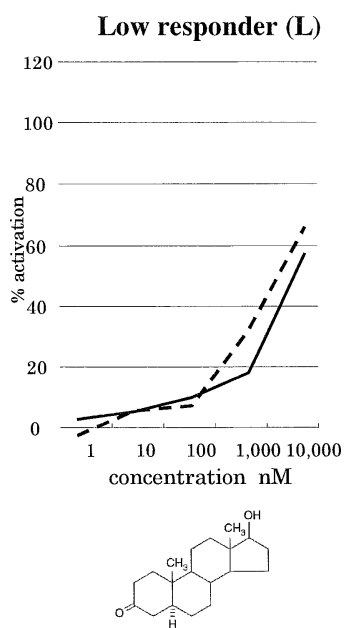

Dihydrotestosterone
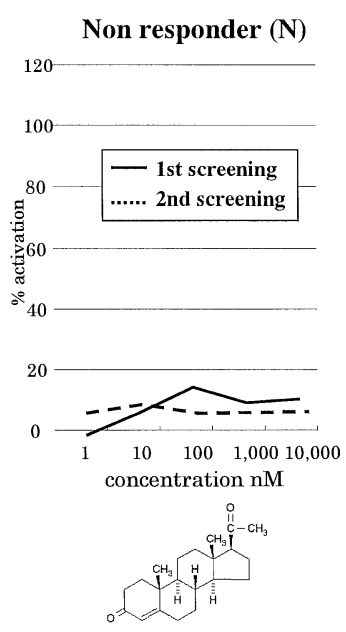

Progesterone

Fig. 9 Three types of chemical responses.

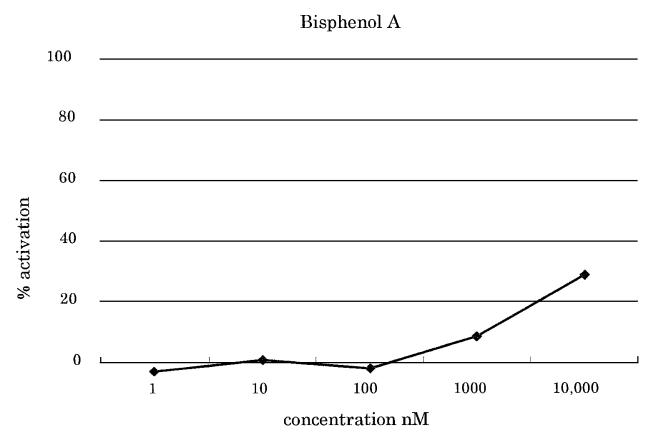

Fig. 10 Results of Bisphenol A.

The difference in the end point level was within 4 RU and the annealing level of anti-ERE was kept constant at around $25 \mathrm{RU}$ throughout 30 cycles (Fig. 7c). We tested the reproducibility by repeating positive and negative controls for 16 cycles. It was shown that the results were with high precision with a CV\% value of $4.68 \%$, as shown in Fig. 8.

\section{Screening results of 30 chemicals}

We tested 30 chemicals to check the dose-dependent activation of the ER binding. One cycle of the assay took 15 min and the screening of one chemical was completed with 9 cycles in $2.5 \mathrm{~h}$, including 5 different concentrations of the test chemicals, the positive and negative controls repeated twice for each control. We calculated the relative activation (\% activation) using the formula shown in Fig. 4 for 30 chemicals. Based on the values of $\%$ activation at $100 \mathrm{nM}$ of each chemical, chemicals could be classified into three groups (Fig. 9): the chemicals that showed more than $50 \%$ of the activation as "high responders", those with $20-50 \%$ as "low responders" and those less than $20 \%$ as "non-responders". The results obtained with two independent sets of screening were summarized in Table 1.28 out of 30 chemicals showed the same results in the first and the second screening. $17 \beta$-Estradiol and its derivatives were classified to "high responders", while male hormones (progesterone) were "non-responders". Bisphenol A which is regarded as one of the endocrine disruptors, was classified among "low responders" (Fig. 10).

Furthermore, the differences in the effect of the chemicals on the ER binding activities were observed in the different shapes of the sensorgrams among those of $17 \beta$-estradiol, bisphenol A, $17 \alpha$-estradiol, diethylstilbestrol (DES), tamoxifen and progesterone (Fig. 11). We have plotted the binding level at the end of the injection of ER in the presence of $1 \mu \mathrm{M}$ of the test chemical ( $\mathrm{Y}$ axis) versus the binding stability $2 \mathrm{~min}$ after the end of the ER injection (X axis), as shown in Fig. 12. We found that the agonists and the antagonists had significantly different patterns. The antagonists (such as tamoxifen) had a tendency to stabilize the binding of ER to ERE. The assay using Biacore indicated the possibility not only to detect the estrogenic activities of the chemicals, but to distinguish the antagonists from the agonists. 

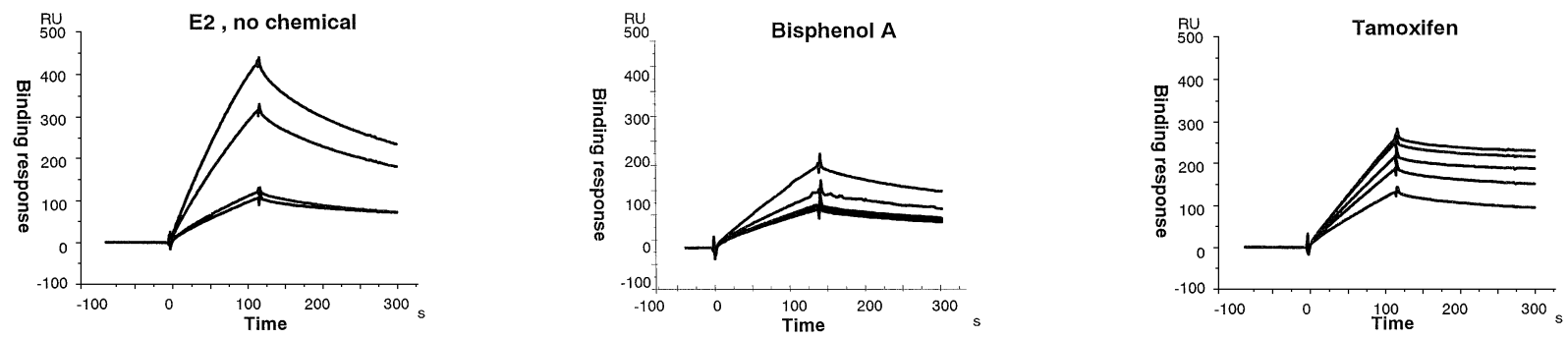

Fig. 11 Different kinetic patterns in the ER-ERE interaction.

Table 1 Results of ER-ERE screening with SPR sensor

\begin{tabular}{|c|c|c|c|c|}
\hline No. & CAS No. & Name & 1st Screening & 2nd Screening \\
\hline 1 & 000050-28-2 & Estradiol & $\mathrm{H}$ & $\mathrm{H}$ \\
\hline 2 & 000057-91-0 & Estra-1,3,5(10)-triene-3,17-diol $(17 \alpha)$ & $\mathrm{H}$ & $\mathrm{H}$ \\
\hline 3 & $000053-16-7$ & Estrone & $\mathrm{H}$ & $\mathrm{H}$ \\
\hline 4 & $000057-63-6$ & 19-Nor-17-alpha-pregna-1,3,5(10)-trien-20-yne-3,17-diol & $\mathrm{H}$ & $\mathrm{H}$ \\
\hline 5 & $000362-05-0$ & Estra-1,3,5(10)-triene-2,3,17-beta-triol & $\mathrm{H}$ & $\mathrm{H}$ \\
\hline 6 & $000362-07-2$ & Estra-1,3,5(10)-triene-3,17-diol, 2-methoxy-, $(17 \beta)$ - & $\mathrm{L}$ & $\mathrm{L}$ \\
\hline 7 & $000068-22-4$ & 19-Nor-17-alpha-pregn-4-en-20-yn-3-one, 17-hydroxy- & $\mathrm{L}$ & $\mathrm{L}$ \\
\hline 8 & 000063-05-8 & Androst-4-ene-3,17-dione & $\mathrm{N}$ & $\mathrm{N}$ \\
\hline 9 & 000057-83-0 & Progesterone & $\mathrm{N}$ & $\mathrm{N}$ \\
\hline 10 & $000501-24-6$ & 3-Pentadecylphenol & $\mathrm{N}$ & $\mathrm{N}$ \\
\hline 11 & 005153-25-3 & Benzoic acid, 4-hydroxy-, 2-ethylhexyl ester & $\mathrm{N}$ & $\mathrm{L}$ \\
\hline 12 & 001034-01-1 & Gallic acid, octyl ester & $\mathrm{N}$ & $\mathrm{N}$ \\
\hline 13 & $006807-17-6$ & 4,4'-(1,3-Dimethylbutylidene) bisphenol & $\mathrm{L}$ & $\mathrm{L}$ \\
\hline 14 & 027955-94-8 & Phenol, 4,4',4"-ethylidynetri- & $\mathrm{N}$ & $\mathrm{N}$ \\
\hline 15 & 000081-92-5 & Benzenemethanol, 2-[bis(4-hydroxyphenyl)methyl]- & $\mathrm{L}$ & $\mathrm{L}$ \\
\hline 16 & $000081-90-3$ & $o$-Toluic acid, .alpha.,.alpha.-bis(p-hydroxyphenyl)- & $\mathrm{N}$ & $\mathrm{N}$ \\
\hline 17 & $000978-86-9$ & 4-(Triphenylmethyl) phenol & $\mathrm{L}$ & $\mathrm{L}$ \\
\hline 18 & 062625-31-4 & $\begin{array}{l}\text { Phenol, 4,4'-(3H-1,2-benzoxathiol-3-ylidene) bis 3-methyl-, S,S-dioxide, } \\
\text { monosod }\end{array}$ & $\mathrm{N}$ & $\mathrm{N}$ \\
\hline 19 & $005384-21-4$ & Phenol, 4,4'-methylenebis[2,6-dimethyl- & $\mathrm{L}$ & $\mathrm{L}$ \\
\hline 20 & 005613-46-7 & 2,6-Xylenol, 4,4'-isopropylidenedi- & $\mathrm{L}$ & $\mathrm{L}$ \\
\hline 21 & $000084-16-2$ & Phenol, 4,4'-(1,2-diethylethylene) di-, meso- & $\mathrm{H}$ & $\mathrm{H}$ \\
\hline 22 & $000084-17-3$ & Phenol, 4,4'-(diethylideneethylene) di- & $\mathrm{L}$ & $\mathrm{H}$ \\
\hline 23 & $56-53-1$ & diethylstilbestrol & $\mathrm{H}$ & $\mathrm{H}$ \\
\hline 24 & 006893-02-3 & Alanine, 3-(4-(4-hydroxy-3-iodophenoxy)-3,5-diiodophenyl)-, L- & $\mathrm{N}$ & $\mathrm{N}$ \\
\hline 25 & 000500-38-9 & Nordihydroguaiaretic acid & $\mathrm{N}$ & $\mathrm{N}$ \\
\hline 26 & 023239-51-2 & $\begin{array}{l}\text { Benzyl alcohol, p-hydroxy-alpha-(1-((p-hydroxyphenethyl)amino)ethyl)-, } \\
\text { hydrochlo }\end{array}$ & $\mathrm{N}$ & $\mathrm{N}$ \\
\hline 27 & $001050-28-8$ & L-Tyrosine, $N$-L-tyrosyl- & $\mathrm{N}$ & $\mathrm{N}$ \\
\hline 28 & $000145-50-6$ & 1(4H)-Naphthalenone, 4 - alpha.-(4-hydroxy-1-naphthyl) benzylidene - & $\mathrm{L}$ & $\mathrm{L}$ \\
\hline 29 & $000446-72-0$ & Genistein & $\mathrm{L}$ & $\mathrm{L}$ \\
\hline 30 & $000080-05-7$ & Bisphenol A & $\mathrm{L}$ & $\mathrm{L}$ \\
\hline
\end{tabular}

H, High responder; L, low responder; N, non-responder.
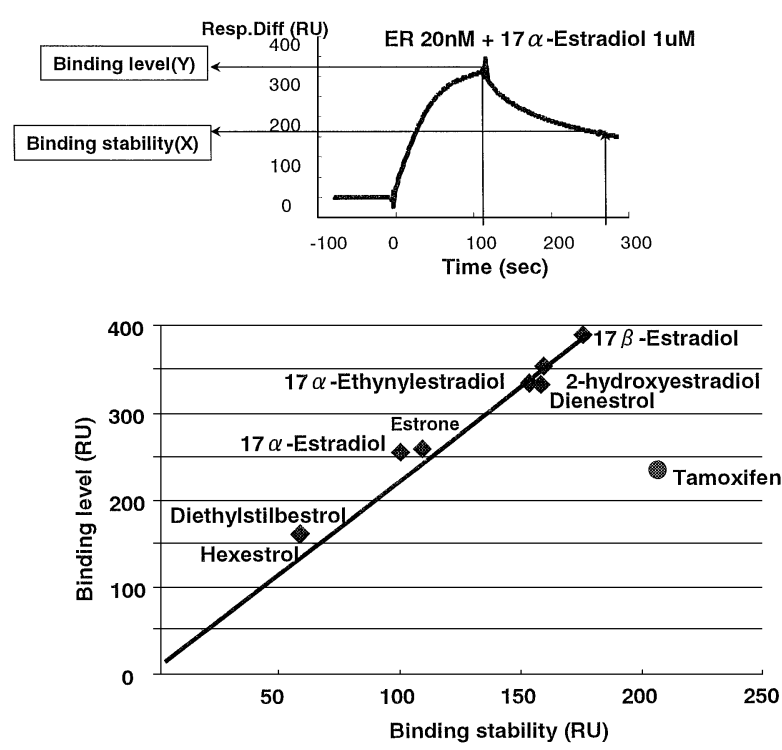

Fig. 12 Binding level vs. binding stability plot.

\section{Discussion}

We established a cell free screening method while focusing on the mechanism of the hormone receptor using a surface plasmon resonance sensor. We developed an assay method to detect estrogenic activities of the chemicals with changes in the binding level of ER to ERE by preincubating the chemicals with ER.

It was also suggested that the agonitst and the antagonists had different effects on the interaction of ER and ERE from an analysis of the binding level of ER during the association and dissociation processes. With the conventional end point assay used to monitor only the binding signals, it was impossible to distinguish the agonists from the antagonists. The real time analysis, which is the main feature of the surface plasmon resonance sensor enabled the classification of the agonists and the antagonists. When running the cell based hormone assay, it must be taken into account any unexpected effects of the chemicals to the other components than the receptors of the cells. On the other hand, the cell free assays simply show the 
direct effects of chemicals to the receptor-signal transduction systems. Our new assay, based on the hormone receptor mechanism, can rapidly screen a large number of the chemicals for their hormonal activities.

Since other hormone receptors employ similar mechanism as ER for the activation of the gene expression, it is possible to develop same assays for other hormone receptors. A newly developed ER assay is both reliable and efficient as a primary screening method of chemicals for estrogenic activities.

\section{Acknowledgements}

This work was supported by Ministry of Health, Labour and Welfare of Japan.

\section{References}

1. "White paper on the endocrine disrupting chemicals ' 99 (Japanese)", Environmental Agency, Japan, 1999.

2. M. Nakai, Y. Tabita, D. Asai, Y. Yakabe, T. Shinmyozu, M. Noguchi, M. Takatsuki, and Y. Shimohigashi, Biochem.
Biophys. Res. Commun., 1999, 254, 311.

3. "The interim report by the committee on the effects on health by the endocrine disrupting chemicals (Japanese)", Ministry of Health and Welfare, Japan, 1998.

4. A. M. Soto and C. Sonnenschein, Biochem. Biophys. Res. Commun., 1984, 122, 1097.

5. M. Pons, D. Gagne, J. C. Nicolas, and M. Mehtali, BioTechniques, 1990, 9, 450.

6. J. R. Reel, I. V. J. C. Lamb, and B. H. Neal, Appl. Toxicol., 1996, 34, 288.

7. OECD, OECD VALIDATION WORK ON IN-VIVO UTEROPHIC SCREENING ASSAY, 1999.

8. "Methods of the Biological Assays of the Endocrine Disrupting Chemicals", ed. T. Inoue, 2000, Springer Verlag, Tokyo.

9. P. Diel, T. Schulz, K. M. molnikar, E. Trunck, G. Ollmer, and H. Ichna, J. Steroid Biochem. Mol. Biol., 2000, 73(12), 1 .

10. "Real-Time Analysis of Biomolecular Interactions", ed. K. Nagata and H. Handa, 1998, Springer Verlag, Tokyo.

11. B. J. Cheskis, S. Karathanasis, and C. R. Lyttle, J. Biol. Chem., 1997, 272, 11384. 